\title{
BMJ Global Health Disease prevalence among nursery school children after the Great East Japan earthquake
}

Mami Ishikuro, ${ }^{1}$ Hiroko Matsubara, ${ }^{2}$ Masahiro Kikuya, ${ }^{1}$ Taku Obara, ${ }^{1}$ Yuki Sato, ${ }^{1}$ Hirohito Metoki, ${ }^{1}$ Tsuyoshi Isojima, ${ }^{3}$ Susumu Yokoya, ${ }^{4}$ Noriko Kato, ${ }^{5}$ Toshiaki Tanaka, ${ }^{6}$ Shoichi Chida, ${ }^{7}$ Atsushi Ono, ${ }^{8}$ Mitsuaki Hosoya, ${ }^{8}$ Hiroshi Yokomichi, ${ }^{9}$ Zentaro Yamagata, ${ }^{9}$ Soichiro Tanaka, ${ }^{10}$ Shigeo Kure, ${ }^{10}$ Shinichi Kuriyama ${ }^{1,2}$

To cite: Ishikuro M, Matsubara H, Kikuya M, et al. Disease prevalence among nursery school children after the Great East Japan earthquake. BMJ Global Health 2017;2:e000127. doi:10.1136/bmjgh-2016000127

Received 15 July 2016 Revised 14 December 2016 Accepted 18 January 2017

CrossMark

For numbered affiliations see end of article.

Correspondence to

Dr Mami Ishikuro;

m_ishikuro@med.tohoku.ac.jp

\section{ABSTRACT}

Objective: To investigate the relationship between personal experience of the Great East Japan Earthquake and various disease types among nursery school children.

Design: We conducted a nationwide survey of nursery school children born between 2 April 2006 and 1 April 2007. Nursery school teachers completed questionnaires if they agreed to join the study. Questionnaire items for children consisted of their birth year and month, sex, any history of moving into or out of the current nursery school, presence of diseases diagnosed by a physician at the age of 66-78 months and type of disaster experience. The survey was conducted from September 2012 to December 2012.

Setting: Japan, nationwide.

Participants: A total of 60270 nursery school children were included in the analysis, 840 of whom experienced the disaster on 11 March 2011.

Main outcome measures: The health status of children 1.5 years after the disaster based on nursery school records.

Results: Experiencing the disaster significantly affected the prevalence of overall and individual diseases. Furthermore, there was a difference in disease prevalence between boys and girls. In boys, experiencing the tsunami $(\mathrm{OR} 2.53,95 \% \mathrm{Cl} 1.22$ to $5.24)$ and living in an evacuation centre (OR 2.92 , $95 \% \mathrm{Cl} 1.46$ to 5.83 ) were remarkably associated with a higher prevalence of atopic dermatitis, but these trends were not observed among girls. Instead, the home being destroyed (OR $3.50,95 \% \mathrm{Cl}$ 2.02 to 6.07 ) and moving house (OR $4.19,95 \% \mathrm{Cl}$ 2.01 to 8.71 ) were positively associated with a higher prevalence of asthma among girls.

Conclusions: Our study indicates that experiencing the disaster may have affected the health status of nursery school children at least up to 1.5 years after the disaster. Continuous monitoring of the health status of children is necessary to develop strategic plans for child health.

\section{Key questions}

What is already known about this topic?

- The Great East Japan Earthquake that occurred on 11 March 2011 caused major damage in a large portion of Eastern Japan, but the few studies conducted mainly analysed psychiatric problems with a small sample size.

- Although children might be especially vulnerable to disasters, there are no broad reports on child health that include more physically oriented or chronic diseases in the postdisaster period of a large-scale earthquake such as the Great East Japan Earthquake or the Sumatra-Andaman Earthquake.

\section{What are the new findings?}

- We found that children who experienced the Great East Japan Earthquake had a higher disease prevalence even 1.5 years after the disaster.

- To the best of our knowledge, this is the first study to reveal that a mega disaster and subsequent disaster experience affect the health of children in the midterm after the disaster.

\section{Recommendations for policy}

- Our results suggest that we need to continue monitoring the health status of children over the long term to identify those who need support in improving their health, and to provide appropriate care continuously.

- Such monitoring would be helpful in the event of future disasters.

\section{INTRODUCTION}

Mega disasters can occur anywhere in the world. The Great East Japan Earthquake that occurred on 11 March 2011 caused major damage in a large portion of Eastern Japan, and in total, 15893 lives were lost and 2567 people remain missing. ${ }^{1}$ Survivors must live with the catastrophic experience for the rest 
of their lives. Soon after the disaster, many hospitalbased studies reported an increase in the prevalence of diseases, such as infectious disease, cardiovascular disease, respiratory disease and mental stress; ${ }^{2-6}$ however, the midterm and long-term impacts of the disaster on public health are still unknown.

Children might be especially vulnerable to disasters. ${ }^{78}$ Limited studies reporting the effects of the Great East Japan Earthquake on child health are available. ${ }^{9}{ }^{10}$ These previous studies mainly analysed psychiatric problems with a small sample size. The Sumatra-Andaman Earthquake in Indonesia was of a similar scale to the Great East Japan Earthquake, bringing serious damage to coastal areas in Indonesia and neighbouring countries in 2004. ${ }^{11} \mathrm{~A}$ few studies of the Sumatra-Andaman Earthquake reported psychiatric problems among children in the postdisaster period. ${ }^{12}{ }^{13}$ However, there are no broad reports on child health that include more physically oriented or chronic diseases in the postdisaster period of a large-scale earthquake, such as the Great East Japan Earthquake or the Sumatra-Andaman Earthquake.

We therefore conducted a nationwide, populationbased study of various diseases among 60270 nursery school children up to 1.5 years after the Great East Japan Earthquake, including 840 children who experienced the disaster, and investigated the relationship between personal disaster experience and various disease types. Since Japan is one of the most developed countries in the world, it is assumed that the advanced medical support system might have contributed to the acute recovery of survivors' health. Regardless, our data are expected to substantially contribute to the long-term health of survivors of this disaster as well as persons affected by future large-scale disasters, including those in developed countries.

\section{METHODS}

The present study is part of the 'Nationwide Nursery School Survey on Child Health throughout the Great East Japan Earthquake', supported by the Ministry of
Health, Labor and Welfare, Japan. The purpose of the survey is to investigate the impact of the Great East Japan Earthquake on the growth and physical and mental health of children.

We asked 23711 authorised nursery schools in all 47 prefectures in Japan to join the study and mailed questionnaires to the 4266 schools that showed interest in participating. Nursery school teachers completed the questionnaires if they finally agreed to join the study. Finally, 3624 nursery schools returned the questionnaires. The survey was conducted from September 2012 to December 2012. The details of the survey have been described elsewhere. ${ }^{14}$ The study protocol was approved by the institutional review board of Tohoku University.

\section{Participants}

Participants of the study were nursery school children born between 2 April 2006 and 1 April 2007 (undergraduate group), as well as nursery school children born between 2 April 2004 and 1 April 2005 (graduate group) (figure 1). Some of the children in the undergraduate group experienced the disaster at the age of 4759 months, but all of the children in the graduate group left nursery school before the disaster occurred. New school terms in Japan start on April 1 and all children in each class are born between April 2 of the current school year and April 1 of the following year. The graduate group was used to compare predisaster disease prevalence in coastal and inland areas most affected by the disaster. We collected data for 69702 children in the undergraduate group and 54558 children in the graduate group. In the graduate group, 3621 children from Iwate, Miyagi and Fukushima Prefectures, the areas most affected by the disaster, were included in the analysis.

\section{Questionnaire}

The questionnaires consisted of three parts, 'A', 'B1' and 'B2'. Part 'A' asked about information on the nursery school itself, such as the degree of damage caused by the disaster and teachers' subjective opinions on the effects of the disaster on children. Parts 'B1' and
Figure 1 Timeline of the study with respect to the Great East Japan Earthquake.

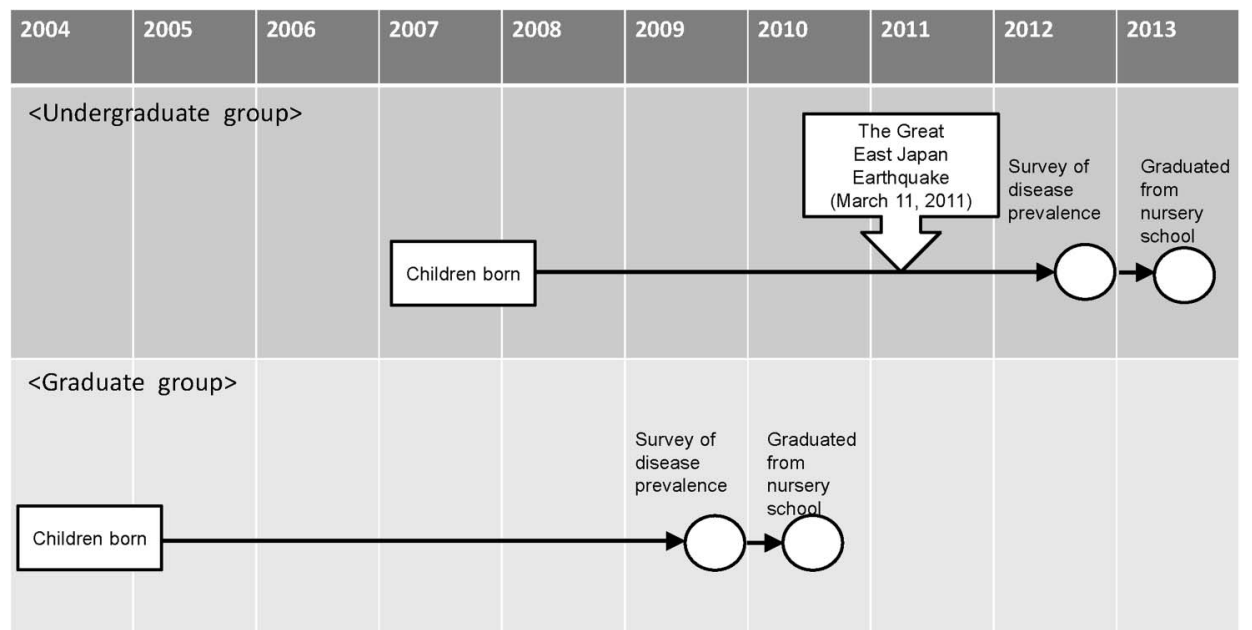


'B2' asked about information on children in the graduate and undergraduate groups, including their birth year and month, sex, any history of moving into or out of the current nursery school and presence of diseases diagnosed by a physician at the age of $66-78$ months. ${ }^{14}$ The date of the diagnosis was not included in this questionnaire.

In addition, part 'B2' for children in the undergraduate group included items on the type of disaster experience ('house destroyed', 'tsunami', 'fire', 'moving house', 'living in an evacuation centre' and 'death in the family'). ${ }^{14}$ 'Moving house' was defined as children having to move to another house from their former house where they lived before the disaster, whereas 'living in an evacuation centre' was defined as children having to stay in an evacuation centre temporarily. The full contents of the questionnaire are available elsewhere. ${ }^{14}$ We used the data from parts 'B1' and 'B2' in this study. Of the 3624 nursery schools that returned questionnaires, 2779 provided responses to part 'B1' and 3561 provided responses to part 'B2'.

\section{Statistical analysis}

We excluded children whose information on sex, disaster experience and disease prevalence was missing. We also excluded children who moved out of their nursery school since the survey was conducted all over Japan and those children might be duplicated in the analysis as children who moved in. We stratified the data by sex. The $\chi^{2}$ test and Fisher's exact test were used to analyse statistical differences in background information appropriately. We performed unconditional logistic regression between experiencing the disaster and current health status by sex. We also performed unconditional logistic regression to investigate whether type of housing among those with tsunami experience was related to disease prevalence because univariate unconditional logistic regression showed different trends for disease prevalence between 'moving house' and 'living in an evacuation centre'. We assumed that living conditions were different between living in a house and living in an evacuation centre, and this might affect the severity of allergic diseases such as asthma or atopic dermatitis. Model 1 used 'tsunami,' 'sex' and 'moving house' and model 2 used 'tsunami,' 'sex' and 'living in an evacuation centre' as covariates. Furthermore, among children in the graduate group, we compared the prevalence of diseases between those living in coastal and inland areas of Iwate, Miyagi and Fukushima Prefectures to investigate whether there was a local secular trend in disease prevalence before the disaster. $p$ Values of $<0.05$ were considered statistically significant. We used the SAS package (V.9.4, SAS Institute, Cary, North Carolina, USA) for all the analyses.

\section{RESULTS}

A total of 60270 nursery school children were eligible for analysis in this study. The participants were recruited from all over Japan (table 1).
Table 1 Distribution of participants throughout Japan

\begin{tabular}{|c|c|c|c|}
\hline Prefecture & $\begin{array}{l}\text { Without disaster } \\
\text { experience }(n)\end{array}$ & $\begin{array}{l}\text { With disaster } \\
\text { experience }(n)\end{array}$ & $\begin{array}{l}\text { Total } \\
\text { (n) }\end{array}$ \\
\hline Hokkaido & 1832 & 4 & 1836 \\
\hline Aomori & 1339 & 13 & 1352 \\
\hline Iwate & 1064 & 93 & 1157 \\
\hline Miyagi & 1645 & 319 & 1964 \\
\hline Akita & 1598 & 7 & 1605 \\
\hline Yamagata & 633 & 30 & 663 \\
\hline Fukushima & 1060 & 184 & 1244 \\
\hline Ibaraki & 937 & 75 & 1012 \\
\hline Tochigi & 1363 & 6 & 1369 \\
\hline Gunma & 1070 & 3 & 1073 \\
\hline Saitama & 2775 & 10 & 2785 \\
\hline Chiba & 2858 & 38 & 2896 \\
\hline Tokyo & 3645 & 9 & 3654 \\
\hline Kanagawa & 2273 & 4 & 2277 \\
\hline Niigata & 2579 & 10 & 2589 \\
\hline Toyama & 939 & 0 & 939 \\
\hline Ishikawa & 843 & 0 & 843 \\
\hline Fukui & 529 & 0 & 529 \\
\hline Yamanashi & 640 & 2 & 642 \\
\hline Nagano & 1083 & 3 & 1086 \\
\hline Gifu & 938 & 0 & 938 \\
\hline Shizuoka & 1883 & 3 & 1886 \\
\hline Aichi & 4758 & 4 & 4762 \\
\hline Mie & 1186 & 1 & 1187 \\
\hline Shiga & 455 & 0 & 455 \\
\hline Kyoto & 396 & 0 & 396 \\
\hline Osaka & 1948 & 2 & 1950 \\
\hline Hyogo & 1272 & 1 & 1273 \\
\hline Nara & 468 & 1 & 469 \\
\hline Wakayama & 155 & 0 & 155 \\
\hline Tottori & 532 & 0 & 532 \\
\hline Shimane & 628 & 0 & 628 \\
\hline Okayama & 1903 & 2 & 1905 \\
\hline Hiroshima & 2500 & 1 & 2501 \\
\hline Yamaguchi & 715 & 0 & 715 \\
\hline Tokushima & 134 & 1 & 135 \\
\hline Kagawa & 703 & 0 & 703 \\
\hline Ehime & 553 & 1 & 554 \\
\hline Kochi & 620 & 1 & 621 \\
\hline Fukuoka & 2769 & 7 & 2776 \\
\hline Saga & 341 & 0 & 341 \\
\hline Nagasaki & 663 & 0 & 663 \\
\hline Kumamoto & 1161 & 2 & 1163 \\
\hline Oita & 425 & 1 & 426 \\
\hline Miyazaki & 791 & 1 & 792 \\
\hline Kagoshima & 702 & 1 & 703 \\
\hline Okinawa & 126 & 0 & 126 \\
\hline Total & 59430 & 840 & 60270 \\
\hline
\end{tabular}


The numbers of boys and girls who experienced the Great East Japan Earthquake were 426 (1.4\%) and 414 $(1.4 \%)$, respectively (table 2 ). The most common disaster experience was 'house destroyed' in boys and girls $(0.5 \%$ and $0.6 \%$, respectively). There was a significant difference in the proportion of boys $(0.3 \%)$ and girls $(0.4 \%)$ who experienced the 'tsunami' (table 2). Since only one child experienced 'fire', we did not include 'fire' in the subsequent analysis for the effects of disaster experience on child health. The numbers of children diagnosed with atopic dermatitis were 1165 boys (3.7\%) and 898 girls (3.1\%), and those for asthma were 1303 boys $(4.2 \%)$ and 727 girls (2.5\%) (table 2). Children with kidney and heart diseases represented $<0.1 \%$ and $0.5 \%$ of the total participants, respectively (table 2 ). We also classified other diseases as 'allergy, Kawasaki disease, total developmental disorder, epilepsy, and others'.

Experiencing the disaster significantly affected disease prevalence among children, and there was a difference in the trend between boys and girls. In boys, experiencing the 'tsunami' (OR 2.53, 95\% CI 1.22 to 5.24) and 'living in an evacuation centre' (OR 2.92, 95\% CI 1.46 to 5.83) were strongly associated with a higher prevalence of atopic dermatitis (tables 3 and 4). No other disaster experiences were significantly associated with the prevalence of asthma. In girls, 'house destroyed' (OR $3.50,95 \%$ CI 2.02 to 6.07 ) and 'moving house' (OR $4.19,95 \%$ CI 2.01 to 8.71 ) were strongly associated with a higher prevalence of asthma (tables 3 and 4). We could not sufficiently investigate the effects of disaster experience on kidney disease, heart disease and Kawasaki disease because the prevalence of these diseases among the study participants was too low for statistical analysis.

Experiencing the 'tsunami' showed a significantly high disease prevalence risk. When comparing disease prevalence risk between 'moving house' and 'living in an evacuation centre', 'living in an evacuation centre' tended to be associated with higher disease prevalence, particularly with atopic dermatitis; however, the difference was not significant (table 5).

Of the 2119 children in the graduate group who were eligible for the analysis of disease prevalence between coastal and inland areas, 639 were living in coastal areas and 1480 were living in inland areas at the time of the disaster. None of the diseases included in this study showed a significant difference in prevalence among children by area $(\mathrm{p}>0.1)$.

\section{DISCUSSION}

We found that nursery school children who experienced the Great East Japan Earthquake had a higher disease prevalence even 1.5 years after the disaster. To the best of our knowledge, this is the first study to reveal that a mega disaster and subsequent disaster experience affect the health of children in the midterm after the disaster.

Since we used the data of diagnoses at a single time point and did not ask the participants whether their diseases were diagnosed before the disaster, we might have

Table 2 Characteristics of the participants

\begin{tabular}{|c|c|c|c|}
\hline & $\begin{array}{l}\text { Boys } \\
n=31238\end{array}$ & $\begin{array}{l}\text { Girls } \\
n=29032\end{array}$ & p Value \\
\hline Disaster experience $(n, \%)$ & $426(1.4)$ & $414(1.4)$ & 0.5 \\
\hline House destroyed (n, \%) & $170(0.5)$ & $172(0.6)$ & 0.4 \\
\hline Tsunami (n, \%) & $90(0.3)$ & $117(0.4)$ & 0.02 \\
\hline Fire $(n, \%)$ & $1(0.003)$ & 0 & 1.0 \\
\hline Moving house (n, \%) & $78(0.3)$ & $83(0.3)$ & 0.4 \\
\hline Living in an evacuation centre $(\mathrm{n}, \%)$ & $89(0.3)$ & $103(0.4)$ & 0.1 \\
\hline Death in the family $(n, \%)$ & $16(0.05)$ & $13(0.04)$ & 0.7 \\
\hline Others (n, \%) & $146(0.5)$ & $122(0.4)$ & 0.4 \\
\hline Disease prevalence $(n, \%)$ & $4136(13.2)$ & $2948(10.2)$ & $<0.0001$ \\
\hline Atopic dermatitis (n, \%) & $1165(3.7)$ & $898(3.1)$ & $<0.0001$ \\
\hline Asthma (n, \%) & $1303(4.2)$ & $727(2.5)$ & $<0.0001$ \\
\hline Heart disease (n, \%) & $129(0.4)$ & $126(0.4)$ & 0.7 \\
\hline Kidney disease $(n, \%)$ & $27(0.09)$ & $13(0.04)$ & 0.047 \\
\hline Other diseases (n, \%) & $2054(6.6)$ & $1483(5.1)$ & $<0.0001$ \\
\hline Allergy & $660(2.1)$ & $416(1.4)$ & $<0.0001$ \\
\hline Kawasaki disease & $94(0.3)$ & $57(0.2)$ & 0.01 \\
\hline Total developmental disorder & $127(0.4)$ & $58(0.2)$ & $<0.0001$ \\
\hline Epilepsy & $61(0.2)$ & $59(0.2)$ & 0.9 \\
\hline Others & 1095 (3.5) & $878(3.0)$ & 0.0009 \\
\hline
\end{tabular}


Table 3 Association between disaster experience and disease prevalence after the disaster

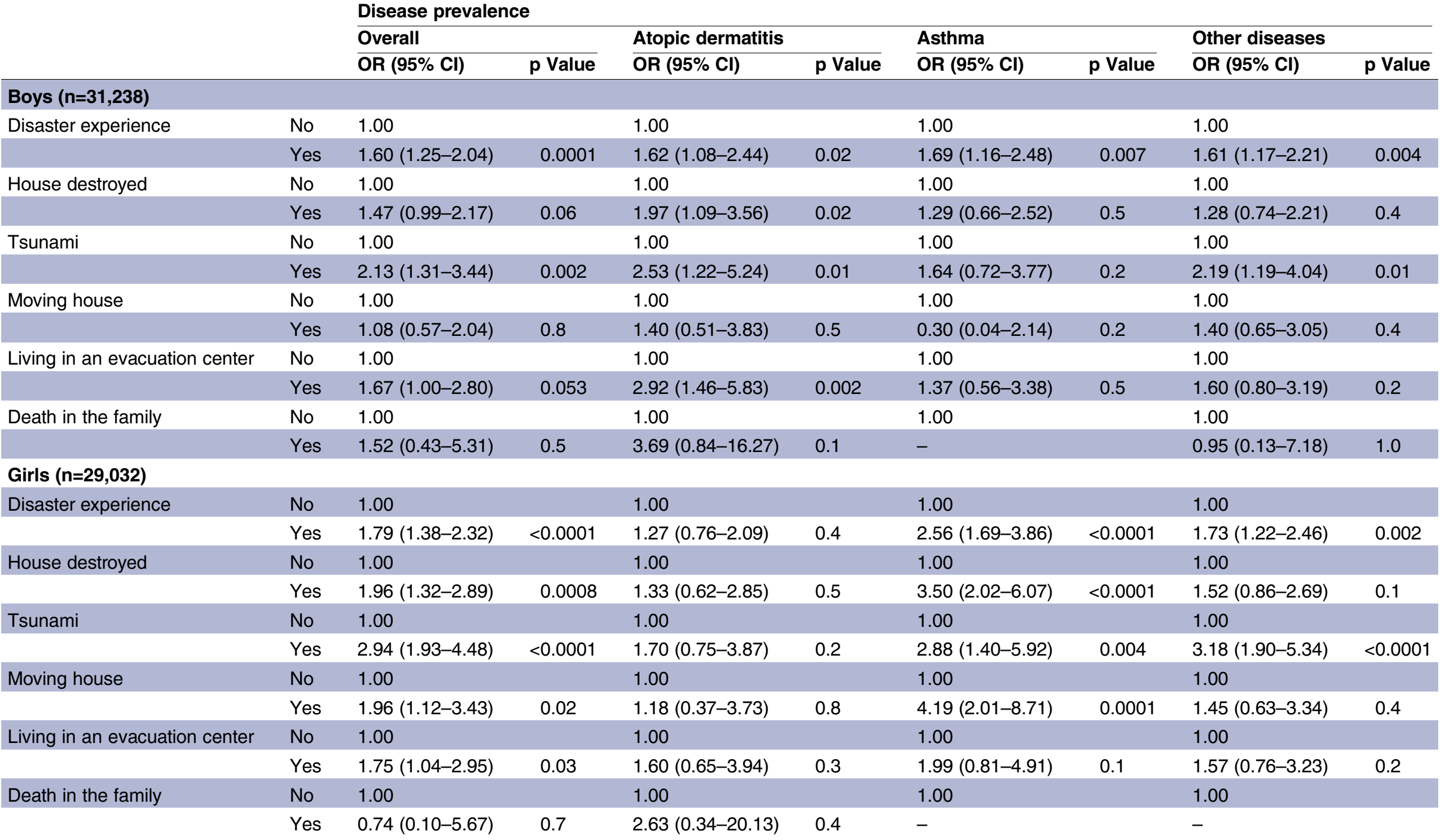

OR, odds ratio; $\mathrm{Cl}$, confidence interval; $\mathrm{P}, \mathrm{P}$ value. Unadjusted, unconditional logistic regression. 


\begin{tabular}{|c|c|c|c|c|c|c|c|c|c|}
\hline & & \multicolumn{8}{|c|}{ Other disease prevalence } \\
\hline & & \multicolumn{2}{|l|}{ Allergy } & \multicolumn{2}{|c|}{ Total developmental disorder } & \multicolumn{2}{|l|}{ Epilepsy } & \multicolumn{2}{|l|}{ Others } \\
\hline & & OR (95\% Cl) & p Value & OR (95\% Cl) & p Value & $\overline{\mathrm{OR}}(95 \% \mathrm{Cl})$ & p Value & OR (95\% Cl) & p Value \\
\hline \multicolumn{10}{|l|}{ Boys $(n=31,238)$} \\
\hline \multirow[t]{2}{*}{ Disaster experience } & No & 1.00 & & 1.00 & & 1.00 & & 1.00 & \\
\hline & Yes & $1.23(0.67-2.25)$ & 0.5 & $1.76(0.56-5.54)$ & 0.3 & $1.21(0.17-8.72)$ & 0.9 & $1.96(1.33-2.89)$ & 0.0007 \\
\hline \multirow[t]{2}{*}{ House destroyed } & No & 1.00 & & 1.00 & & 1.00 & & 1.00 & \\
\hline & Yes & $1.41(0.58-3.44)$ & 0.5 & $2.95(0.72-12.01)$ & 0.1 & $3.06(0.42-22.19)$ & 0.3 & $1.01(0.45-2.28)$ & 1.0 \\
\hline \multirow[t]{2}{*}{ Tsunami } & No & 1.00 & & 1.00 & & 1.00 & & 1.00 & \\
\hline & Yes & $1.05(0.26-4.29)$ & 0.9 & - & & - & & $3.46(1.79-6.70)$ & 0.0002 \\
\hline \multirow[t]{2}{*}{ Moving house } & No & 1.00 & & 1.00 & & 1.00 & & 1.00 & \\
\hline & Yes & $1.86(0.58-5.90)$ & 0.3 & $3.2(0.44-23.18)$ & 0.3 & - & & $1.10(0.35-3.50)$ & 0.9 \\
\hline \multirow[t]{2}{*}{ Living in an evacuation center } & No & 1.00 & & 1.00 & & 1.00 & & 1.00 & \\
\hline & Yes & $2.19(0.80-5.99)$ & 0.1 & - & & - & & $1.64(0.67-4.06)$ & 0.3 \\
\hline \multirow[t]{2}{*}{ Death in the family } & No & 1.00 & & 1.00 & & 1.00 & & 1.00 & \\
\hline & Yes & - & & $16.45(2.16-125.50)$ & 0.007 & - & & - & \\
\hline \multicolumn{10}{|l|}{ Girls $(n=29,032)$} \\
\hline \multirow[t]{2}{*}{ Disaster experience } & No & 1.00 & & 1.00 & & 1.00 & & 1.00 & \\
\hline & Yes & $2.09(1.17-3.74)$ & 0.01 & - & & $1.19(0.17-8.63)$ & 0.9 & $1.73(1.11-2.70)$ & 0.02 \\
\hline \multirow[t]{2}{*}{ House destroyed } & No & 1.00 & & 1.00 & & 1.00 & & 1.00 & \\
\hline & Yes & $2.51(1.10-5.70)$ & 0.03 & - & & - & & $1.37(0.64-2.92)$ & 0.4 \\
\hline \multirow[t]{2}{*}{ Tsunami } & No & 1.00 & & 1.00 & & 1.00 & & 1.00 & \\
\hline & Yes & $2.45(0.90-6.67)$ & 0.1 & - & & - & & $4.05(2.27-7.24)$ & $<0.0001$ \\
\hline \multirow[t]{2}{*}{ Moving house } & No & 1.00 & & 1.00 & & 1.00 & & 1.00 & \\
\hline & Yes & $2.59(0.82-8.24)$ & 0.1 & - & & - & & $1.20(0.38-3.82)$ & 0.8 \\
\hline \multirow[t]{2}{*}{ Living in an evacuation center } & No & 1.00 & & 1.00 & & 1.00 & & 1.00 & \\
\hline & Yes & $0.68(0.09-4.84)$ & 0.7 & - & & $4.88(0.67-35.57)$ & 0.1 & $1.99(0.87-4.55)$ & 0.1 \\
\hline \multirow[t]{2}{*}{ Death in the family } & No & 1.00 & & 1.00 & & 1.00 & & 1.00 & \\
\hline & Yes & - & & - & & - & & - & \\
\hline
\end{tabular}

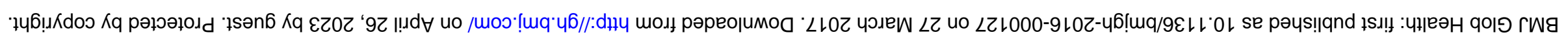


Table 5 OR of 'moving house' and 'living in an evacuation centre' with tsunami experience as the disaster experience

\begin{tabular}{llc}
\hline & OR $(95 \%$ Cl $)$ & p Value \\
\hline $\begin{array}{l}\text { Disease prevalence } \\
\text { Model 1 }\end{array}$ & \\
$\quad$ Tsunami & $2.56(1.81$ to 3.61$)$ & $<0.0001$ \\
\hline $\begin{array}{l}\text { Sex (female) } \\
\text { Moving house }\end{array}$ & $0.74(0.70$ to 0.78$)$ & $<0.0001$ \\
\hline $\begin{array}{l}\text { Model 2 } \\
\quad \text { Tsunami }\end{array}$ & $0.97(0.61$ to 1.54$)$ & 0.9 \\
\hline $\begin{array}{l}\text { Sex (female) } \\
\text { Living in an evacuation } \\
\text { centre }\end{array}$ & $0.74(0.70$ to 0.78$)$ & $<0.0001$ \\
\hline
\end{tabular}

Atopic dermatitis

\begin{tabular}{|c|c|c|}
\hline \multicolumn{3}{|l|}{ Model 1} \\
\hline Tsunami & 2.14 (1.19 to 3.86$)$ & 0.01 \\
\hline Sex (female) & $0.82(0.75$ to 0.90$)$ & $<0.0001$ \\
\hline Moving house & 0.92 (0.40 to 2.09$)$ & 0.8 \\
\hline \multicolumn{3}{|l|}{ Model 2} \\
\hline Tsunami & 1.60 (0.85 to 3.02$)$ & 0.1 \\
\hline Sex (female) & $0.82(0.75$ to 0.90$)$ & $<0.0001$ \\
\hline $\begin{array}{l}\text { Living in an evacuation } \\
\text { centre }\end{array}$ & $1.82(0.96$ to 3.43$)$ & 0.1 \\
\hline \multicolumn{3}{|l|}{ Asthma } \\
\hline \multicolumn{3}{|l|}{ Model 1} \\
\hline Tsunami & 2.03 (1.12 to 3.69$)$ & 0.02 \\
\hline Sex (female) & 0.59 (0.54 to 0.65$)$ & $<0.0001$ \\
\hline Moving house & $1.28(0.61$ to 2.68$)$ & 0.5 \\
\hline \multicolumn{3}{|l|}{ Model 2} \\
\hline Tsunami & 2.08 (1.12 to 3.87$)$ & 0.02 \\
\hline Sex (female) & 0.59 (0.54 to 0.65$)$ & $<0.0001$ \\
\hline $\begin{array}{l}\text { Living in an evacuation } \\
\text { centre }\end{array}$ & $1.14(0.55$ to 2.37$)$ & 0.7 \\
\hline
\end{tabular}

Other diseases

\begin{tabular}{|c|c|c|}
\hline \multicolumn{3}{|l|}{ Model 1} \\
\hline Tsunami & 2.79 (1.82 to 4.28$)$ & $<0.0001$ \\
\hline Sex (female) & 0.76 (0.71 to 0.82$)$ & $<0.0001$ \\
\hline Moving house & 0.88 (0.47 to 1.65$)$ & 0.7 \\
\hline \multicolumn{3}{|l|}{ Model 2} \\
\hline Tsunami & 2.75 (1.76 to 4.31$)$ & $<0.0001$ \\
\hline Sex (female) & 0.76 (0.71 to 0.82$)$ & $<0.0001$ \\
\hline $\begin{array}{l}\text { Living in an evacuation } \\
\text { centre }\end{array}$ & 0.95 (0.53 to 1.68$)$ & 0.8 \\
\hline
\end{tabular}

Model 1: adjusted for experiencing the tsunami, sex and moving house.

Model 2: adjusted for experiencing the tsunami, sex and living in an evacuation centre.

included children who already had the disease before the Great East Japan Earthquake occurred. Nevertheless, our analysis of the graduate group showed that disease prevalence in the coastal and inland areas most affected by the disaster was not significantly different from each other. Although we have to interpret these results cautiously, they might indicate that mega disasters affect child health at least in the midterm.

There are no previous studies analysing the effects of mega disasters, such as the Sumatra-Andaman Earthquake, on child health from a broad perspective. However, a previous study of a mild disaster in rural India found that children aged under 5 years who experienced a natural disaster in the previous month showed an increased likelihood of acute respiratory illness. ${ }^{15}$ This was consistent with our finding of a higher risk of asthma among children who experienced the disaster compared with those who did not, and furthermore, we observed a higher disease prevalence even at 17 months after the disaster, which was longer than the previous study.

We used data from a nationwide nursery school survey of a large study population because we speculated that some children might have moved out of the disaster area to a less affected area. We found that about $30 \%$ of children who had experienced the disaster were living in less disaster-stricken areas than Iwate, Miyagi and Fukushima Prefectures (table 1). This indicates that in order to fully investigate the impact of a disaster on child health, the study area should include the disaster area and a much wider region.

Nursery schools in Japan are commonly used childcare facilities, and they routinely collect information about the children who attend them to understand their health status, including the diagnosis of any diseases. Japanese nursery teachers are licensed by the government or have graduated from schools certified by the Minister of Health, Labour and Welfare and are qualified to collect accurate information regarding child health. Therefore, we believe that the information on diagnosed diseases collected in this study had no recall bias and relatively sufficient accuracy for the analysis.

It should be noted that the Japanese government applied a medical fee reduction to assist individuals affected by the Great East Japan Earthquake in paying for medical costs; this may have resulted in these individuals visiting doctors more often, thereby increasing the likelihood that any diseases would be diagnosed. However, most municipalities throughout Japan normally apply a medical fee reduction for children in addition to any disaster-related deduction, so patient behaviour between those affected and unaffected by the disaster in this nationwide survey was probably not considerably different. Furthermore, although medical fee reductions could have raised disease prevalence, the prevalence of each disease studied showed a different response pattern to the disaster; therefore, medical reductions are thought to have had a limited effect on this phenomenon.

The mechanism for differences in disease prevalence between boys and girls was unclear. The most plausible 
explanation for these differences might be chance. Nevertheless, a previous study in Japan found that among neonates, more boys have atopic dermatitis than girls. ${ }^{16}$ Furthermore, Saunes et $a l^{17}$ reported a stronger positive association between mental distress and atopic dermatitis in boys compared with girls among adolescents aged 13-19 years. Their findings might indicate that stressful situations may stimulate the development of atopic dermatitis in boys more than in girls. From the perspective of asthma, a previous study investigating asthma in model mice showed that the sex difference in allergic airway inflammation may be attributable to immune cells. ${ }^{18}$ That study demonstrated a higher sensitivity for the development of allergen-induced airway inflammation in female mice compared with male mice. ${ }^{18}$ Therefore, the sex differences in asthma prevalence observed in this study might be explained by immunological system responses to stress caused by experiencing the disaster.

We also investigated whether 'moving house' and 'living in an evacuation centre' had different disease prevalence trends after adjusting for experiencing the 'tsunami', which was a potential risk for disease prevalence based on the univariate unconditional logistic regression, since the univariate unconditional logistic regression showed a different trend for health status between these two variables. The results indicated that experiencing the 'tsunami' itself still had a greater risk of disease prevalence and asthma. A cross-sectional survey conducted about 1 month after the Sumatra-Andaman Earthquake found that children aged under 5 years had a higher proportion of acute diseases such as upper respiratory tract infections and trauma than other ages. ${ }^{19}$ Our results suggest that experiencing the 'tsunami' might have affected the prevalence of various diseases among children, even in the midterm after the disaster. In contrast, the difference in disease prevalence between those who experienced 'moving house' and 'living in an evacuation centre' was not statistically significant. However, 'living in an evacuation centre' tended to be positively associated with a higher prevalence of atopic dermatitis than 'moving house'. Moreover, the OR of experiencing the 'tsunami' with 'living in an evacuation centre' was not statistically significant and was lower than the OR with 'moving house'. Microbes (ie, Staphylococcus aureus) and aeroallergens are known factors for atopic dermatitis. ${ }^{20}$ We assume that children who experienced life in an evacuation centre could not take a bath or shower sufficiently because most of the evacuation centres were public facilities such as schools, municipal offices and community halls. A previous questionnaire survey of children's caregivers after the Great East Japan Earthquake also showed that children had exacerbated atopic dermatitis because they could not take a bath. ${ }^{21}$ Evacuation centres were also used by many people, so the type and concentration of aeroallergens might have differed from living in a house. The aeroallergens in houses are more easily controlled than in an evacuation centre because life can more closely resemble daily life at home before the disaster occurred. However, we cannot overestimate our results, and further evaluation of the effects of housing environment is necessary. We also need to investigate whether 'living in an evacuation centre' after experiencing a tsunami, which is also a factor of skin problems, ${ }^{22}$ causes atopic dermatitis.

This study had some limitations. First of all, we collected data from only about $15.0 \%$ of all nursery schools in Japan, so the results might be biased due to the selection of participants. However, the participating nursery schools were spread all over Japan, including areas not directly affected by the disaster, and we received many responses from nursery schools with children without any disaster experience. ${ }^{14}$ Therefore, we believe that our study population was minimally biased and most likely reflects the health status of nursery school children. On the other hand, we did not conduct a survey of children who went to kindergartens, which are governed by the School Education Act, or children who did not attend nursery school or kindergarten. Although nursery schools do not limit the age of entry, and more than $40.0 \%$ of preschool children aged 3 years or older in Japan go to a nursery school, ${ }^{23}$ we must also investigate the health status of children who attended kindergartens and ensure that they receive care, if necessary. Furthermore, we did not include school-aged children, whose developmental stage might be different from that of preschool children, in our survey. In a previous study, Miyashita $e t a l^{24}$ reported that the prevalence of eczema symptoms among children in the second and eighth grades after the Great East Japan Earthquake was higher compared with the average in Japan, and experiencing the 'tsunami' was significantly associated with a high prevalence of eczema. Our results might support the possibility that children overall who experience a mega disaster could experience negative health effects. Continuous monitoring and more detailed research on children's health are necessary. Second, we asked teachers in nursery schools about the children's experience with the tsunami, so we could not determine whether the children had indeed been swept up in tsunami waves or just saw the tsunami from a distance. Therefore, we might not have observed the direct effects of the tsunami on child health. If we could classify tsunami experience in more detail, the direct and indirect effects could be identified. Nevertheless, we still observed the effects of experiencing the tsunami on child health. Finally, we asked about the presence of some diagnosed diseases with an open-ended question in the questionnaire; therefore, some diseases might have been missed. This means that more diseases affected by the disaster could be identified.

Our results suggest that we need to continue monitoring the health status of children over the long-term to identify those who need support in improving their health, and to provide appropriate care continuously. Furthermore, such monitoring would be helpful in the 
event of future disasters. Natural disasters can occur anytime, anywhere. ${ }^{25}{ }^{26}$ The number of natural disasters in recent years is triple that of the $1980 \mathrm{~s} .{ }^{27}$ However, widespread devastation can be prevented through better disaster preparedness. ${ }^{26}$ The Sendai Framework for Disaster Risk Reduction mentions that 'developing the capacity of health workers in understanding disaster risk and applying and implementing disaster risk reduction approaches in health work' is important as an investment in disaster risk reduction. ${ }^{28}$ Our results indicate that disease prevalence in children differs by sex as well as by type of disaster experience. Therefore, health workers should collect background information to provide better care. In particular, tsunami experience should be considered as a factor of developing diseases.

In conclusion, experiencing the Great East Japan Earthquake may affect the health status of nursery school children up to $\sim 1.5$ years after the disaster.

\author{
Author affiliations \\ ${ }^{1}$ Tohoku Medical Megabank Organization (ToMMo), Tohoku University, \\ Sendai, Japan \\ ${ }^{2}$ Department of Disaster Public Health, International Research Institute of \\ Disaster Science, Tohoku University, Sendai, Japan \\ ${ }^{3}$ Department of Pediatrics, Graduate School of Medicine, The University of \\ Tokyo, Tokyo, Japan \\ ${ }^{4}$ National Center for Child Health and Development, Tokyo, Japan \\ 5 Jumonji University, Niiza, Japan \\ ${ }^{6}$ Tanaka Growth Clinic, Tokyo, Japan \\ ${ }^{7}$ Department of Pediatrics, School of Medicine, Iwate Medical University, \\ Morioka, Japan \\ ${ }^{8}$ Department of Pediatrics, School of Medicine, Fukushima Medical University, \\ Fukushima, Japan \\ ${ }^{9}$ Department of Health Sciences, University of Yamanashi, Chuo, Japan \\ ${ }^{10}$ Department of Pediatrics, Graduate School of Medicine, Tohoku University, \\ Sendai, Japan
}

\section{Handling editor Masoud Mirzaei.}

Acknowledgements The authors wish to express their appreciation to the nursery teachers who completed questionnaires, as well as to Dr lkuo Endo, President of the Japan Society for Well-being of Nursery-schoolers, for their support and cooperation.

Collaborators The following are members of the working group for childhood physical development evaluation: SKure (PI), SY, TT, NK, TI, SC, MH, AO, ZY, HY, ST, SKuri, MK, MI, HMa.

Contributors All authors were involved in this study. SKure, SKuri, SC and $\mathrm{MH}$ created the study design. SKure, ST, SKuri, MK, MI and HMa collected and cleaned the data. SKuri, MK, HMe, TO, MI, YS and HMa analysed the data. MI, HMa, MK, TO, YS, HMe, TI, SY, NK, TT, SC, AO, MH, HY, ZY, ST, SKure and SKuri interpreted the data.

Funding The 'Nationwide Nursery School Survey on Child Health throughout the Great East Japan Earthquake' was conducted as a part of the 'Surveillance Study on Child Health in the Great East Japan Earthquake Disaster Area' and supported in full by the Health and Labour Sciences Research Grant (H24-jisedai-shitei-007, fukkou).

Disclaimer The funder had no role in the design and conduct of the study. All authors have independence of research from the funders.

Competing interests None declared.

Ethics approval The institutional review board of Tohoku University.

Provenance and peer review Not commissioned; externally peer reviewed.
Data sharing statement No additional data are available.

Open Access This is an Open Access article distributed in accordance with the Creative Commons Attribution Non Commercial (CC BY-NC 4.0) license, which permits others to distribute, remix, adapt, build upon this work noncommercially, and license their derivative works on different terms, provided the original work is properly cited and the use is non-commercial. See: http:// creativecommons.org/licenses/by-nc/4.0/

\section{REFERENCES}

1. Report on damage by the Great East Japan Earthquake. Tokyo: National Police Agency, 2015. https://www.npa.go.jp/archive/keibi/ biki/higaijokyo.pdf (accessed 12 Nov 2015).

2. Kitamura T, Kiyohara K, Iwami T. The great east Japan earthquake and out-of-hospital cardiac arrest. N Engl J Med 2013;369:2165-7.

3. Aoki T, Fukumoto Y, Yasuda S, et al. The Great East Japan Earthquake Disaster and cardiovascular diseases. Eur Heart $J$ 2012;33:2796-803.

4. Ohkouchi S, Shibuya R, Yanai M, et al. Deterioration in regional health status after the acute phase of a great disaster: respiratory physicians' experiences of the Great East Japan Earthquake. Respir Investig 2013;51:50-5.

5. Tohma K, Suzuki A, Otani K, et al. Monitoring of influenza viruses in the aftermath of the Great East Japan earthquake. Jpn J Infect Dis 2012;65:542-4.

6. Matsubara $\mathrm{C}$, Murakami $\mathrm{H}$, Imai $\mathrm{K}$, et al. Prevalence and risk factors for depressive reaction among resident survivors after the tsunami following the Great East Japan Earthquake, March 11, 2011. PLoS ONE 2014;9:e109240.

7. Brandenburg M, Watkins S, Brandenburd K, et al. Operation Child-ID: reunifying children with their legal guardians after Hurricane Katrina. Disasters 2007;31:277-87.

8. Nishikiori N, Abe T, Costa DG, et al. Who died as a result of the tsunami? Risk factors of mortality among internally displaced persons in Sri Lanka: a retrospective cohort analysis. BMC Public Health 2006;6:73.

9. Fujiwara T, Yagi J, Homma H, et al., Great East Japan Earthquake Follow-up for Children Study Team. Clinically significant behavior problems among young children 2 years after the Great East Japan Earthquake. PLOS ONE 2014;9:e109342.

10. Tatsuta N, Nakai K, Satoh H, et al. Impact of the Great East Japan earthquake on child's intelligence quotient. J Pediatr 2015;167:745-51

11. Doocy S, Daniels A, Dick A, et al. The human impact of tsunamis: a historical review of events 1900-2009 and systematic literature review. PLoS Curr 2013;5: ecurrents.dis. f4deb457904936b07c09daa98ee8171a.

12. Thienkrua W, Cardozo BL, Chakkraband ML, et al. Symptoms of posttraumatic stress disorder and depression among children in tsunami-affected areas in southern Thailand. JAMA 2006;296:549-59.

13. Piyasil V, Ketumarn P, Prubrukarn R, et al. Post-traumatic stress disorder in children after the tsunami disaster in Thailand: a 5-year follow-up. J Med Assoc Thai 2011;94(Suppl 3):S138-44.

14. Matsubara $\mathrm{H}$, Ishikuro $\mathrm{M}$, Kikuya $\mathrm{M}$, et al. Design of the nationwide nursery school survey on child health throughout the Great East Japan earthquake. J Epidemiol 2016;26:98-104.

15. Datar A, Liu J, Linnemayr S, et al. The impact of natural disasters on child health and investments in rural India. Soc Sci Med 2013;76:83-91.

16. Japanese Society of Allergology. Guidelines for the management and atopic dermatitis 2009. Tokyo: Kyowa Planning, 2009.

17. Saunes M, Smidesang I, Holmen TL, et al. Atopic dermatitis in adolescent boys is associated with greater psychological morbidity compared with girls of the same age: the Young-HUNT study. $\mathrm{Br}$ J Dermatol 2007;156:283-8.

18. Okuyama K, Wada K, Chihara J, et al. Sex-related splenocyte function in a murine model of allergic asthma. Clin Exp Allergy 2008;38:1212-9.

19. Guha-Sapir D, van Panhuis WG, Lagoutte J. Short communication: patterns of chronic and acute diseases after natural disasters-a study from the International Committee of the Red Cross field hospital in Banda Aceh after the 2004 Indian Ocean tsunami. Trop Med Int Health 2007;12:1338-41.

20. Morren MA, Przybilla B, Bamelis M, et al. Atopic dermatitis: triggering factors. J Am Acad Dermatol 1994;31(3 Pt 1): 467-73.

21. Yamaoka A, Hayashi C, Watanabe $Y$, et al. The questionnaire for caregivers of allergic children in area affected by Tsunami in the 
Great East Japan Earthquake. Nihon Shoni Arerugi Gakkaishi 2013;27:93-106.

22. Lee SH, Choi CP, Eun HC, et al. Skin problems after a tsunami. $J$ Eur Acad Dermatol Venereol 2006;20:860-3.

23. Cabinet Secretariat [Internet]. Tokyo: The status of the implementation of preschool education and childcare (cited 20 November 2016). http:// www.cas.go.jp/jp/seisaku/youj/dai2/sankou1.pdf (in Japanese).

24. Miyashita M, Kikuya M, Yamanaka C, et al. Eczema and asthma symptoms among schoolchildren in coastal and Inland areas after the 2011 Great East Japan Earthquake: the ToMMo
Child Health Study. Tohoku J Exp Med 2015;237:

297-305.

25. McCall C. Remembering the Indian Ocean tsunami. Lancet 2014;384:2095-8.

26. The next era of disaster risk reduction. Lancet 2015;385:2016

27. Leaning J, Guha-Sapir D. Natural disasters, armed conflict, and public health. N Engl J Med 2013;369:1836-42.

28. United Nations Office for Disaster Risk Reduction (UNISDR). Sendai framework for disaster risk reduction 2015-2030. 1st edn. Geneva, Switzerland: UNISDR, 2015 